\title{
Expanded Abstracts
}

\author{
Journal of \\ Epilepsy and \\ Clinical \\ Neurophysiology
}

J Epilepsy Clin Neurophysiol 2012;18(2):50-52

\section{A Caracterização do Perfil de Expressão Gênica em Larga Escala em Modelos Genéticos de Epilepsia Fornece Elementos para Entender os Mecanismos Envolvidos na Epileptogênese em Roedores*}

\author{
Matos AHBa, Pascoal VDBa, Nascimento DR ${ }^{\mathrm{b}}$, Martins $\mathrm{S}^{\mathrm{b}}$, Rocha CS, Vasconcellos JFa , Chamma MT', \\ Maurer-Morelli CVa, Martins ASb², Valle ACc, Godard ALB ${ }^{d}$, Lopes-Cendes I ${ }^{a}$
}

UNICAMP, USP e UFMG

\begin{abstract}
RESUMO
Objetivo: $\mathrm{O}$ objetivo desse trabalho foi caracterizar e comparar o perfil genético de dois modelos de epilepsia em roedores (Wistar Audiogenic Rat - WAR e generalized epilepsy with absence seizures - GEAS) através da análise da expressão gênica em larga escala. Métodos: Para a análise do perfil de expressão gênica foi utilizada a técnica de microarranjos de DNA (microarray). Resultados: Na linhagem WAR a análise do perfil de expressão mostrou que dentro os genes mais hiperexpressos está o Neurod1, envolvido com o desenvolvimento do ducto coclear. Além desse encontramos também diferenças significativas na expressão dos genes Apbb1, Foxg1 e Scn1A. Já nos animais GEAS os genes com maior expressão diferencial foram àqueles relacionados com o desenvolvimento do sistema nervoso central, além de genes envolvidos com a via da MAPK, fatores de transcrição, migração neuronal e apoptose. Conclusão: Esta análise pode ajudar a esclarecer o mecanismo molecular subjacente que leva a predisposição a crises nesses animais. Até o momento, nossos resultados apontam para a ativação de vias moleculares distintas em ambos os modelos.
\end{abstract}

Unitermos: Rato Wistar audiogênico, microarranjos, modelos animais.

\begin{abstract}
Gene expression profiling in genetic animal models of provide elements to unveil the molecular mechanisms underlying epileptogenesis in rodents

Objective: The objective of this study was to characterize and compare the genetic profile of two rodent models of epilepsy (Wistar Audiogenic Rat - WAR and rats with generalized epilepsy with absence seizuresGEAS) using gene expression analysis Methods: We used microarray technology for gene expression analysis. Results: The analysis of gene expression profiles in WAR showed among genes up-regulated Neurod1, involved in the development of the cochlear duct. In addition, we found significant differences in gene expression of Apbb1, Foxg1 and Scn1A. GEAS rats had differentially expressed genes related to the development of central nervous system, as well as genes involved in the MAPK pathway, transcription factors, neuronal migration and apoptosis. Conclusion: This study may help to clarify the underlying molecular mechanism that leads to the predisposition to seizures in these animals. Our results indicate the activation of distinct molecular pathways in both models.
\end{abstract}

Keywords: Wistar audiogenic rat, microarray, animal model.

*Trabalho concorrente ao Prêmio Aristides Leão no XXXIV Congresso Brasileiro de Epilepsia - 06-09 de junho de 2012, Ribeirão Preto, SP.

a Departamento de Genética Médica, Faculdade de Ciências Medicas, Universidade Estadual de Campinas - UNICAMP, Campinas, SP, Brasil.

b Departamento de Patologia, Escola de Medicina, Universidade de São Paulo - USP, São Paulo, SP, Brasil.

c Departamento de Fisiologia e Biofísica, Instituto de Ciências Biológicas, Universidade Federal de Minas Gerais - UFMG, Belo Horizonte, MG, Brasil.

d Departamento de Biologia, Instituto de Ciências Biológicas, Universidade Federal de Minas Gerais - UFMG, Belo Horizonte, MG, Brasil.

Received Apr. 28, 2012; accepted Apr. 30, 2012. 


\section{INTRODUÇÃO}

A utilização de modelos experimentais de epilepsia tem contribuído para um melhor entendimento da fisiopatologia das epilepsias seja in vitro quanto in vivo. Nos modelos genéticos em roedores são geralmente necessários pelo menos dois fatores combinados para a ocorrência de crise. $\mathrm{O}$ primeiro seria uma predisposição geneticamente determinada [mutação(ões) em gene(s)] resultando em uma anormalidade em sistemas essências para a manutenção do balanço excitação-inibição no sistema nervoso central (ex. anormalidade em neurotransmissores associados com os sistemas colinérgico, catecolaminérgico, serotoninérgico e/ou de aminoácidos). O segundo fator que pode ou não estar envolvido (dependendo da magnitude do efeito genético), também chamado de iniciador, inclui estímulos do meio ambiente tais como: luz intermitente, som, hipertermia, infecções, alterações neuroquímicas endógenas ou um desequilíbrio hormonal (Jobe et al., 1981). Portanto, para o aparecimento de uma crise epiléptica, em modelos genéticos, é geralmente necessário (mas não obrigatório) uma predisposição inata à crise somada a um ou mais iniciadores exógenos ou endógenos. Dentro desse modelo é possível que um animal nunca venha a sofrer uma crise epiléptica devido i) a falta de predisposição (genética) ou ii) do(s) estímulo iniciador(es) (Aicardi et al., 1980).

A linhagem WAR (Wistar Audiogenic Rat) é susceptível a crises audiogênicas depois de estimulações sonoras de alta intensidade (Garcia-Cairasco e Sabbatini, 1983; Doretto et al., 2003; Mesquita et al., 2005; Gitaí et al., 2010). Após essas estimulações os animais apresentam crises do tipo tônico-clônicas generalizadas, que se caracterizam por episódios de corridas, pulos e quedas atônicas, seguidas de convulsão tônica, convulsões clônicas parciais e generalizadas e espasmos clônicos, tais eventos fazem parte das crises audiogênicas agudas. Após a repetição contínua dos estímulos sonoros, novas áreas do cérebro começam a ser integradas e os animais passam a apresentar crises límbicas (Moraes et al., 2000).

Outro modelo genético, recentemente identificado, que apresenta epilepsia generalizada do tipo ausência com crises espontâneas (generalized epilepsy with absence seizures, GEAS) (Valle, em preparação), mostra padrão comportamental e eletroencefalográfico distinto de outros modelos já descritos (Bruno-Neto et al. 1999a,b; Nunes et al. 1999; André et al. 1999). Nesses animais, também não foi identificado até o momento nenhum fator iniciador para as crises.

O objetivo do presente estudo foi caracterizar e comparar o perfil genético dessas duas linhagens através da analise da expressão gênica em larga escala. Pretendemos com esse estudo identificar vias moleculares envolvidas nos mecanismos de predisposição à epilepsia (epileptogênese) nesses animais.

\section{MÉTODOS}

Foi obtido o RNA total de cinco WAR susceptíveis (hipocampo e placa quadrigêmia), e dois WAR resistentes, bem como hipocampo de três ratos GEAS e três Wistar controles. Para análise do perfil de expressão gênica foi utilizado o Gene Chip ${ }^{\circledR}$ Rat Genome 2302.0 Array (Affymetrix ${ }^{\mathrm{TM}}$ ), que contém 31.042 transcritos de modo a cobrir todo o genoma transcrito do rato. Além das lâminas mencionadas, foram usados os kits One-Cycle Target Labeling and Control e Hybridization Wash and Stain para a obtenção do cDNA, cRNA, marcação, hibridização, detecção e lavagem. A leitura dos chips foi feita através do Gene Chip Scanner 3000 (Affymetrix ${ }^{\mathrm{TM}}$ ) e o processamento de dados foi feito em ambiente $\mathrm{R}$ com pacotes Affy e Rank Prod do programa Bioconductor. A análise da representação gênica foi realizada através do programa DAVID e a correlação e a interação de vias moleculares foram identificadas com o programa Ingenuity Pathways Analysis.

\section{RESULTADOS}

O enriquecimento gênico ontológico identificou na linhagem WAR genes envolvidos com o desenvolvimento neuronal, regulação da transmissão sináptica, projeção neuronal e sinalização celular. As vias de sinalização mais ativas foram a de desenvolvimento do ducto coclear (gene Neurod1 hiperexpresso) e receptor de sinalização GABA (gene Gabra6 hiperexpresso). Os principais genes com a expressão alterada e possível papel biológico na epileptogênese foram Apbb1, Foxg1 e Scn1A.

Nos animais GEAS foram identificados 45 genes expressos diferencialmente, entre eles estão aqueles relacionados com o desenvolvimento do sistema nervoso central, genes envolvidos com a via da MAPK, fatores de transcrição, migração neuronal e apoptose como Nrsn1, Hspb1, Fos, Twist1 e Krt18. As principais categorias do enriquecimento ontológico incluíram genes ligados a sinalização peptídica, região extracelular e processamento e apresentação do antígeno. As vias de sinalização mais ativadas foram às denominadas como doenças do sistema endócrino, doenças gastrointestinais, ciclo celular e desenvolvimento do sistema nervoso, as quais incluem os genes, Prlr, Hspb1, Igfpb2, CD74 e Fos.

\section{DISCUSSÃO}

Nossos resultados indicam algumas vias moleculares e gene de interesse diferencialmente expressos nos modelos estudados. Entre eles podemos destacar o gene Foxg1 (Forkhead Box G1) que tem sua expressão aumentada (foldchange $=2,8583$ ) vezes na placa quadrigêmea dos animais WAR susceptíveis em comparação com os 
controles. Interessantemente, em publicação recente Brunetti-Pierri (2011), relatou que duplicação na região cromossômica onde o homólogo humano desse gene está localizado produz manifestação clínica caracterizada por déficit cognitivo e epilepsia, sendo que em alguns casos o diagnóstico sindrômico foi de síndrome de Rett. Outro gene que deve ser discutido é o Beta2/Neurod1, que também se encontra com a expressão aumentada em WAR quando comparado com o grupo controle (foldchange $=1,8166$ ). Este tem sido envolvido com neurogênese, diferenciação e manutenção neuronal (Cho and Tsai, 2004).

Nos animais GEAS observou- se que o gene Fos (FBJ osteosarcoma oncogene) está com a expressão alterada no hipocampo (foldchange $=-16,035)$. É digno de nota que Kovács e cols. (2007), trabalhando com a linhagem de ratos Wistar Albino Glaxo/Rijswijk (WAG/Rij), também considerada um modelo genético de epilepsia ausência obervou alterações na expressão do gene Fos.

\section{CONCLUSÃO}

Acreditamos que o tipo de análise global realizada aqui pode ajudar a esclarecer de maneira mais compreensiva o mecanismo molecular subjacente que leva a predisposição a crises nesses animais. Vias identificadas em nosso estudo podem ser subsequentemente estudadas mais profundamente. Além disso, a interação entre os diversos mecanismos moleculares identificados podem fornecer um panorama mais realista da complexidade envolvida na epileptogênese. É interessante notar que nossos resultados apontam claramente para ativação de vias moleculares distintas nos modelos estudados.

\section{REFERÊNCIAS}

Aicard J. Course and prognosis of certain chidhood epilepsies with predominantly myoclonic seizures. Wada JA, Penry JK e cols. Advances in epileptology. The $\mathrm{X}^{\text {th }}$ Epilepsy International Symposim. New York: Ravem; 1980. p. 159-63.

André ES et al. Electrophysiological characterization of a new form of spontaneous epilepsy in Wistar rats. Epilepsia. 1999;40(Suppl. 2).

Bruno-Neto R et al. Caracterização de uma nova forma de epilepsia espontânea em ratos Wistar. XIV FESBE, anais, 1999.

Bruno-Neto R, André ES, Pellarin L, Hilário FK, Valle AC, Timo-Iaria C. Electrophysiological characterization of a new form of spontaneous epilepsy in Wistar rats. 23 ${ }^{\text {rd }}$ International Epilepsy Congress, Prague, Czech Republic; 1999.

Doretto MC, Fonseca CG, Lobo RB, Terra VC, Oliveira JA, GarciaCairasco N. Quantitative study of the response to genetic selection of the WistarAudiogenic Rat strain (WAR). Behav Genet. 2003;33(1): $33-42$.

Garcia-Cairasco N, Sabbatini R. Role of the substantianigra in audiogenic seizures: a neuroethological analysis in the rat. Braz J Med Biol Res. 1983;16(2):171-83.

Gitaí DL, Martinelli HN, Valente V, Pereira MG, Oliveira JA, Elias CF, Bittencourt JC, Leite JP, Costa-Neto CM, Garcia-Cairasco N, PaçóLarson ML. Increased expression of GluR2-flip in the hippocampus of the Wistaraudiogenic rat strain after acute and kindled seizures. Hippocampus. 2010;20:125-33.

Jobe PC, Brown RD, Dailey JW. Effect of Ro 4-1284 on audiogenic seizure susceptibility and intensity in epilepsy-prone rats. Life Sci. 1981; 28(18):2031-8.

Kovács $\mathrm{Z}$ et al. Suppression of spike-wave discharge activity and c-fos expression by2-methyl-4-oxo-3H-quinazoline-3-acetyl piperidine (Q5) in vivo. Neuroscience Letters. 2007;423:73-7.

Mesquita F, Aguiar JF, Oliveira JA, Garcia-Cairasco N, Varanda WA. Electrophysiological properties of cultured hippocampal neurons from WistarAudiogenic rats. Brain Res Bul. 2005;65:177-83

Moraes MF, Galvis-Alonso OY, Garcia-Cairasco N. Audiogenic kindling in the Wistar rat: a potential model for recruitment of limbic structures. Epilepsy Research. 2000;39:251-9.

Nunes PV, Valle AC, Timo-Iaria, C. Epileptogenic potentials recorded from the cerebellar cortex in rats. In $23^{\text {th }}$ International Epilepsy Congress, Prague, Czech Republic. Epilepsia; 1999. v. 40, p. 132.

Endereço para correspondência:

Iscia Lopes Cendes

Departamento de Genética Médica, Faculdade de Ciências Médicas

Universidade Estadual de Campinas - UNICAMP

Rua Tessália Vieira de Camargo, 126 - Cidade Universitária "Zeferino Vaz"

CEP 13083-887, Campinas, SP, Brasil

E-mail: icendes@unicamp.br 